\title{
Estudo de validação de uma medida de avaliação da motivação para alunos do ensino fundamental
}

\author{
Sueli Edi Rufini - Universidade Estadual de Londrina, Londrina, Brasil \\ José Aloyseo Bruneck - Universidade Estadual de Londrina, Londrina, Brasil \\ Katya Luciane de Oliveira - Universidade Estadual de Londrina, Londrina, Brasil
}

\begin{abstract}
Resumo
O objetivo deste estudo foi elaborar e validar um instrumento de avaliação da qualidade motivacional de estudantes do ensino fundamental, tendo por referência a Teoria da Autodeterminação. Inicialmente, com o propósito de obter dados para a elaboração de itens, foram entrevistadas 20 crianças acerca dos motivos alegados para irem à escola. Com base nessas informações e de itens disponíveis na literatura, chegou-se a uma versão preliminar da escala, composta de 30 itens e aplicada para um grupo de 30 crianças. Após os ajustes, responderam à versão final da escala 1381 estudantes do ensino fundamental do estado do Paraná. A análise fatorial exploratória resultou na exclusão de 4 itens do instrumento, ficando um total de 25. Foram aceitáveis os índices de consistência interna para as dimensões avaliadas (desmotivação $\alpha=0,85$, motivação extrínseca por regulação externa $\alpha=0,67$, por regulação introjetada $\alpha=0,76$, por regulação identificada $\alpha=0,88$ e motivação intrínseca $\alpha=0,81$ ). Novas investigações estão em andamento.

Palavras-chave: Motivação, Motivação intrínseca, Motivação extrínseca, Autodeterminação.
\end{abstract}

Validation study of the valuation's measure of motivation for elementary school students

\begin{abstract}
The aim of this study was to develop and validate an instrument for assessing the motivational quality of elementary school students, with reference to the Self-determination Theory. Initially, the purposes of obtaining data for the preparation of items, 20 children were interviewed about the alleged reasons for going to school. Based on this information and items available in the literature, it reached a preliminary version of the scale included 30 items and applied to a group of 30 children. After the adjustments, they answered the final version of the 1381 students in of Compulsive Work. The results showed that from the sociodemographic variables, only Compulsive Work. The results showed that from the sociodemographic variables, only elemetary school in the state of Parana. Factor analysis resulted in the exclusion of four items of the instrument, leaving a total of 25. It was acceptable the indices of internal consistency for the dimensions tested $(\alpha=0.85$ amotivation, extrinsic motivation by external regulation of $\alpha=0.67$ for $\alpha=0.76$ introjected regulation, identified regulation by $\alpha=0.88$ and intrinsic motivation $\alpha=0.81$ ). Further investigations are underway.

Keywords: Motivation, Intrinsic Motivation, Extrinsic Motivations, Self-determination.
\end{abstract}

A motivação do aluno é um determinante crítico do nível e da qualidade da aprendizagem e do desempenho no contexto escolar. Segundo a literatura (Bong, 2001; Guimarães \& Boruchovitch, 2004; Reeve, Deci \& Ryan, 2004; Reeve, 2004; Ryan \& Deci, 2000; Ryan \& Patrick, 2001), a motivação intrínseca resulta em um envolvimento do aluno com as atividades escolares sem a influência de qualquer fator externo, sejam recompensas, pressões, ameaças ou outros. A atividade é, desse modo, valorizada por si mesma, o que inclui um componente afetivo, freqüentemente identificado com interesse.

A Teoria da Autodeterminação, desenvolvida nos últimos trinta anos, tem sido considerada um referencial útil e produtivo para a compreensão e intervenção nos problemas motivacionais presentes na escola (Reeve, 2004). Nessa perspectiva são enfatizadas as fontes motivacionais naturais dos seres humanos, a

\footnotetext{
${ }^{1}$ Endereço para correspondência:

Rodovia Celso Garcia Cid, Km 380 - Caixa Postal 6001.

CEP: 86051-980. Londrina PR.

E-mail: sueli_rufini@hotmail.com
}

sua natureza ativa, a tendência para o crescimento, para o desenvolvimento saudável e para a autorregulação. Para atingir tal nível evolutivo, a pessoa é impulsionada a buscar atividades interessantes que possibilitam o desenvolvimento de habilidades e o exercício de suas capacidades, que representam oportunidades de buscar e de estabelecer vínculos sociais e, sobretudo, permitam alcançar um sentido unificado do self, mediante a integração de experiências intrapsíquicas e interpessoais (Reeve, Deci \& Ryan, 2004; Guimarães \& Boruchovitch, 2004; Ryan \& Deci, 2000). No entanto, o contexto social nem sempre fortalece tal propensão positiva, principalmente quando são ameaçadas as percepções pessoais de competência, de autonomia e de vínculo.

Deci e Ryan (1991) (ver também Ryan \& Deci, 2000) observaram que a motivação humana era tradicionalmente diferenciada em intrínseca e extrínseca. No primeiro caso, o comportamento é motivado pela atividade em si, ou seja, pela satisfação a ela inerente. Já a motivação extrínseca se faz presente quando a atividade for exercida por seu valor instrumental, ou seja, quando for percebida como meio 
para alcançar algo desejável ou para escapar de alguma conseqüência aversiva. A motivação extrínseca era até então menos elaborada, tratada na literatura clássica como um constructo unitário e simplesmente contraposta à motivação intrínseca.

Entretanto, os resultados das investigações empíricas levaram os autores da teoria da autodeterminação a distinguirem tipos diversos de regulação do comportamento, a qual varia em função do nível de autonomia ou autodeterminação percebida (Deci \& Ryan, 1985; 1991). Com esse critério, podem identificar-se graus de autodeterminação na própria motivação extrínseca.

Segundo a Teoria da Autodeterminação, a autorregulação do comportamento segue um continuum com as várias possibilidades de motivação humana. Primeiro, configura-se o nível de desmotivação, caracterizado pela ausência de intenção ou motivação. A seguir, abre-se a condição possível de motivação extrínseca na qual, porém, se verifica uma gradação de autorregulação, que começa por um estado de completa regulação externa Nessa condição, a pessoa simplesmente atende a controladores externos, como no caso de fazer uma tarefa por pressão, ou por mera obediência, ou visando alguma recompensa, ou para evitar punições. A seguir, vem a motivação extrínseca por regulação introjetada, em que as pressões são internas ao indivíduo. A pessoa é motivada a agir para evitar sentimento de culpa, ansiedade ou para atender a instâncias ligadas à auto-estima. Essas duas primeiras formas de regulação externa tipicamente não são autodeterminadas ou autônomas, mas sim tipos diferenciados de motivação controlada, uma externamente e outra internamente.

Como terceiro nível de motivação extrínseca, a regulação identificada consiste em a pessoa considerar certo comportamento como de importância pessoal, aceitando sua regulação como própria. Um bom exemplo é de um adolescente que tem como meta de vida tornar-se escritor e, por isso, assume como valor próprio praticar leitura e redação. A seguir, como tipo mais autônomo de motivação extrínseca vem a regulação integrada, que se caracteriza pelo comportamento assumido por escolha pessoal, com completa autonomia e sem coação, visto como algo pessoalmente importante, porque assimilado ao próprio self. Tal forma de regulação está muito próxima da própria motivação intrínseca, a qual, porém, se distingue por encerrar o componente específico de interesse pela atividade, com componente afetivo, além da ocorrência de liberdade de escolha (Ryan \& Deci, 2000). Na motivação extrínseca por regulação integrada, apesar de ser considerada com um nível relativo de autonomia, há necessidade de um componente externo que dá sentido e ímpeto para a ação. Por exemplo, para um aluno de mestrado, a meta de elaborar seu trabalho de dissertação com qualidade pode ser integrada aos seus valores pessoais, de tal modo que ele não distinga facilmente exigências externas das suas próprias. Todavia, caso o diploma de mestre não fosse mais atrelado à apresentação do trabalho ele provavelmente não persistiria na ação. Csikszentmihalyi (1992) afirma que a diferença entre motivação extrínseca e intrínseca pode ser esclarecida com a resposta dada para a questão: Caso a pessoa não obtenha qualquer consequencia com a realização da atividade, mesmo assim continuaria persistindo e se esforçando nela? Se a resposta for positiva temos aî motivação intrínseca, ao contrário, a motivação extrínseca está presente, mesmo que a regulação do comportamento tenha sido internalizada e esteja alinhada aos valores e metas pessoais.

Os resultados das pesquisas sobre a motivação dos estudantes confirmam uma crença baseada no senso comum de que, à medida que avançam nas séries, os alunos se tornam gradativamente menos motivados para estudar (Harter, 1981; Lepper \& Handerlong, 2000; Lepper, Handerlong \& Iyengard, 2005), sobretudo em áreas de conteúdos específicos como ciências e matemática. Ryan e Deci (2000) afirmam que há uma evidente diminuição da motivação intrínseca dos alunos no decorrer dos oito primeiros anos escolares. Em contraste, como observaram Lepper, Handerlong e Iyengard (2005), há um crescente envolvimento apenas extrínseco dos estudantes com a escola, ou seja, com o avanço nas séries ficam mais evidentes as pressões externas, a competição e a busca por recompensas, o que, por suposição, tende a promover a motivação extrínseca.

No Brasil verifica-se um progressivo aumento de investigações sobre o tema e, ao mesmo tempo, levantaram questionamentos de natureza metodológica. Nas pesquisas que se propuseram avaliar apenas os dois pólos opostos de motivação, os indicadores de validade das escalas têm sido abaixo do recomendado ou não se encontra homogeneidade no conteúdo dos itens de avaliação para cada fator. Por exemplo, no estudo de Martinelli e Bartholomeu (2007), a análise fatorial encontrou 11 fatores, que explicavam 65,10\% da variância total dos dados. Nesse estudo, porém, foram considerados apenas dois fatores, com valores próprios mais altos e com explicação de $35 \%$ da variância das respostas. No entanto, ao se analisar o conteúdo dos itens, verificou-se que alguns correspondem aos tipos qualitativamente diferenciados, propostos pela teoria da autodeterminação. Desta forma, o item da escala "estudo para agradar mens pais on meus professores" não é simplesmente representativo de 
uma motivação extrínseca, mas poderia ser melhor qualificado como de motivação extrínseca por regulação introjetada.

Neves e Boruchovitch (2007) também buscaram levantar as propriedades psicométricas de itens de avaliação da motivação intrínseca e extrínseca. Nessa investigação, foram considerados dois fatores que explicavam $30,39 \%$ da variância da escala. Também neste caso, os itens que se agruparam em torno dos dois fatores correspondem a tipos diferenciados de motivação extrínseca, previstos no continuum de autodeterminação. Diante disso, as autoras sugeriram que outros estudos buscassem superar esta limitação.

Por outro lado, os resultados de alguns estudos sobre a motivação intrínseca de estudantes (Martini, 1999; Arcas, 2003; Neves \& Boruchovitch, 2004), utilizando diferentes técnicas de coleta de informações, suscitaram questionamentos acerca do decréscimo motivacional, pois indicaram preferência dos alunos pela motivação intrínseca ao progredirem nas séries escolares. São necessárias, pois, como ressaltaram os próprios autores desses trabalhos, mais pesquisas para esclarecer o problema, uma vez que seus resultados não se alinham com os de outros autores.

Podem contribuir para esse objetivo a elaboração e o refinamento de instrumentos de coleta de informações, uma vez que instrumentos diferentes de medida de um constructo podem produzir resultados diferentes e até contraditórios. Daí também a necessidade de se construir escalas de mensuração que gozem das propriedades psicométricas e assim se revelem válidas para a nossa realidade, ao lado do exame sistemático de variáveis relacionadas à motivação no contexto escolar.

Diante desse quadro, buscou-se com o presente estudo elaborar e validar um instrumento de avaliação da qualidade motivacional de estudantes do ensino fundamental. O referencial para a elaboração dos itens foi a teoria da autodeterminação (Ryan \& Deci, 2000). Seus autores propuseram um modelo em que a motivação se diferencia qualitativamente não apenas entre intrínseca e extrínseca, mas de acordo com um continuum de autorregulação. Após uma possível condição de ausência de qualquer regulação pessoal (desmotivação), configuram-se pelo menos três níveis de motivação extrínseca (regulação externa, regulação introjetada e regulação identificada), terminando na motivação intrínseca, caracterizada por total autorregulação. O instrumento elaborado avaliará cada nível constante do continuum e sua validação contribuirá para o avanço de pesquisas brasileiras a respeito do tema, além de buscar apoio empírico para a pertinência do próprio modelo teórico.

\section{Método}

\section{Participantes}

Participaram da pesquisa 1381 estudantes do ensino fundamental da região norte do estado do Paraná. Desse total, 691 (50,03\%) do gênero masculino e $669(48,44 \%)$ do gênero feminino; $715(51,77 \%)$ de escola pública e $661(47,86)$ de escola particular; 115 $(8,32 \%)$ da quarta série, $331(23,96 \%)$ da quinta série, $326(23,60 \%)$ da sexta série, $251(18,17 \%)$ da sétima série e $353(25,56 \%)$ da oitava série do ensino fundamental; quanto à idade cronológica, 192 (13,90\%) estavam na faixa de 8 a 10 anos, $518(37,50 \%)$, na de 11 a 12 anos, outros 555 (40,18\%), de 13 a 14 anos, 88 $(6,37 \%)$ de 15 a 16 anos e $4(0,28 \%)$, de 17 anos ou mais.

\section{Instrumento}

Como primeiro passo, foram entrevistadas 20 crianças, com o objetivo de levantar informações acerca dos principais motivos alegados para ir à escola e para conhecer seu vocabulário. Com base nessas informações e de itens disponíveis na literatura (Harter, 1981; Lepper \& Henderlong, 2000; Reeve, Deci \& Ryan, 2004; Ryan \& Deci, 2000; Sobral, 2003; Vallerand \& colaboradores, 1992), foi elaborada uma versão preliminar de um questionário com 30 afirmativas, em escala Likert de cinco pontos, representados por figuras geométricas de tamanhos crescentes, acompanhadas de números de 1 a 5 , que significam, respectivamente, nada verdadeiro até totalmente verdadeiro. Em uma aplicação piloto, 30 crianças foram instruídas a indicar dificuldades na compreensão do conteúdo ou na forma de realizar a atividade. Como resultado, um item foi excluído e alguns termos substituídos. A versão final da escala de avaliação da motivação, após a pergunta inicial 'Por que venho à escola?', compunha-se de 29 afirmativas, representando o continuum proposto pela teoria da autodeterminação (Ryan \& Deci, 2000), do qual foram considerados a hipótese de desmotivação e quatro tipos de motivação, sendo tres de motivação extrínseca em seus diferentes níveis de autorregulação e a própria motivação intrínseca. Importante ressaltar que não foram incluídos itens de avaliação da motivação extrínseca por regulação integrada porque, este tipo de motivação extrínseca é raro entre adolescentes (Niemiec \& colaboradores, 2006), além de ser difícil a construção de itens que consigam captar a sutil diferença entre este e a regulação identificada e motivação intrínseca (Alonso \& colaboradores, 2006; Guimarães \& Bzuneck, 2008). Exemplo dos itens da subescala de desmotivação era o enunciado: Não sei por que venho à escola. De motivação extrínseca por 
regulação externa: Venho à escola para responder à chamada. De regulação introjetada: Se não vier à escola meus pais ficam tristes, chateados. De regulação identificada: Venho à escola para aprender e, por último, de motivação intrínseca: Venho porque eu gosto de vir à escola.

\section{Procedimentos}

O projeto passou pelo Comitê de Ética da Instituição, portanto, estavam respaldadas pela Resolução 196/96 do Conselho Nacional de Saúde e seus complementares. Todas as etapas da coleta de informações foram precedidas por autorização escrita do diretor da escola e dos pais, além de ser dada às crianças a opção de não participarem da pesquisa, caso não o quisessem. Os levantamentos de dados ocorreram em grupo, na sala de aula, nos intervalos ou mediante a liberação de uma parte do horário da aula pelo professor. Foram gastos em média 20 minutos para a aplicação do questionário.

\section{Resultados}

Os 29 itens do instrumento original foram submetidos à análise fatorial com extração dos componentes principais e com rotação varimax. A Tabela 1 mostra os que resultaram seis fatores, com valor próprio (eigenvalue) maior que 1, respondendo por $62,83 \% \%$ da variância nos escores dos participantes.

Tabela 1 - Extração dos componentes principais com autovalor maior do que 1

\begin{tabular}{lcccc}
\hline Fator & Autovalor & \% variância & autovalor acumulado & $\%$ acumulada \\
\hline 1 & 8,42 & 29,03 & 8,42 & 29,03 \\
2 & 4,52 & 15,58 & 12,94 & 44,61 \\
3 & 1,89 & 6,52 & 14,83 & 51,13 \\
4 & 1,18 & 4,08 & 16,01 & 55,21 \\
5 & 1,16 & 4,00 & 17,17 & 59,21 \\
6 & 1,05 & 3,63 & 18,22 & 62,84 \\
\hline
\end{tabular}

Utilizou-se também do scree test para avaliar a conveniência da manutenção do número de fatores a serem utilizados (Figura 1). Considerando principalmente a coerência teórica dos itens e o gráfico de sedimentação, apresentado na Figura 1, trabalhou-se com a hipótese de seis fatores como uma possível configuração para a escala. $\mathrm{Na}$ presente análise, para que um item do questionário pudesse carregar num fator, estabeleceu-se como critério o valor de corte de 0,30. De acordo com Kline (1994), este é um valor aceitável, dado que explicaria pelo menos 9\% da variância total.

Para a decisão pela resolução final dos itens relacionados a cada fator, levou-se em consideração, além da carga fatorial de cada item em relação ao fator, a coerência teórica para o agrupamento e o critério de se contar com número igual de itens na composição de cada subescala representativa dos pontos do continuum. Desta forma, alguns itens da escala original foram excluídos. Primeiro, foi descartado o item 22 porque, originalmente concebido para avaliação da motivação extrínseca por regulação introjetada, agrupou-se com itens de motivação extrínseca por regulação identificada. Excluiu-se também o item 15 por ter apresentado a menor carga fatorial dos seis itens que originalmente carregaram no Fator 3. Foi também rejeitado o item 19 por ter carregado em relação a três fatores. Finalmente, foi desconsiderado o item 28, o único com carga fatorial no Fator 6, porém de significado aparentemente estranho aos pontos do continum, pela conotação de meta de relacionamento social na escola. Portanto, a escala final fechou com 25 itens, com cinco em cada um dos cinco fatores, o que se pode ver na Tabela 2 .

Os índices de consistência interna entre os itens de cada subescala, medidos pelo alfa de Cronbach, foram: desmotivação 0,85 , motivação extrínseca por regulação externa 0,67 , por regulação introjetada 0,76 , por regulação identificada 0,88 e motivação intrínseca 0,81 . 


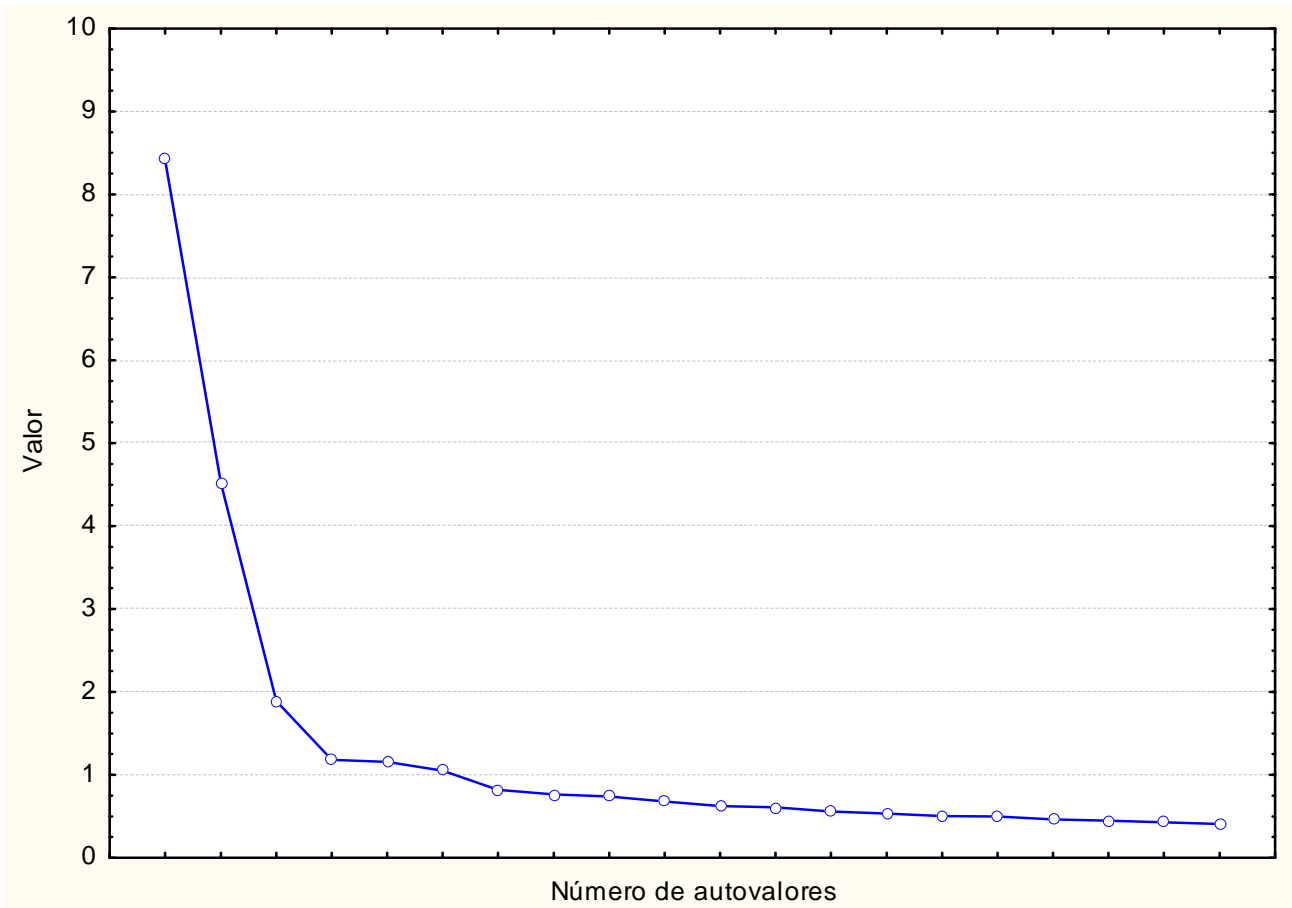

Figura 1. Representação dos escores dos autovalores de cada fator (método do Diagrama de autovalores)

Tabela 2. Distribuição dos Itens por Fator com a Respectiva Carga Fatorial

\begin{tabular}{|c|c|c|c|c|c|c|}
\hline & \multicolumn{6}{|c|}{ Fatores } \\
\hline Item & 1 & 2 & 3 & 4 & 5 & 6 \\
\hline 13.Venho à escola porque é aqui que se aprende & 0,69 & & & & & \\
\hline 17.Venho à escola para aprender & 0,78 & & & & & \\
\hline 21.Venho para a escola porque é importante para o meu futuro & 0,85 & & & & & \\
\hline 22. Tenho que mostrar para mim mesmo que sou bom aluno & 0,61 & & & & & \\
\hline 23.Venho à escola para aprender mais & 0,79 & & & & & \\
\hline 24.Venho à escola para ser alguém na vida & 0,82 & & & & & \\
\hline 3.Venho à escola porque meus pais querem que eu venha & & 0,49 & & & & \\
\hline 4.Venho à escola porque meus pais mandam & & 0,46 & & & & \\
\hline 6.Se eu não vier à escola meus pais ficam tristes, chateados & & 0,69 & & & & \\
\hline 11.Venho à escola porque meus pais ficam alegres & & 0,70 & & & & \\
\hline 27.Venho à escola senão meus pais ficam bravos comigo & & 0,70 & & & & \\
\hline 1.Não sei, acho que não tem nada para se fazer na escola & & & 0,70 & & & \\
\hline 2.Tenho preguiça de ir à escola & & & 0,63 & & & \\
\hline 8.Não sei porque venho, eu acho a escola chata & & & 0,75 & & & \\
\hline 10.Não sei porque eu venho à escola, eu não gosto & & & 0,78 & & & \\
\hline 15.Antes eu gostava de vir à escola, mas agora não gosto mais & & & 0,59 & & & \\
\hline 18.Não tenho vontade de vir à escola & & & 0,67 & & & \\
\hline 7.Venho à escola para não ficar em casa & & & & 0,53 & & \\
\hline 9.Venho para não me chamarem de burro & & & & 0,50 & & \\
\hline 12.Venho à escola para responder à chamada & & & & 0,73 & & \\
\hline 14.Venho à escola para não receber faltas & & & & 0,79 & & \\
\hline 26. Venho à escola para não reprovar & & & & 0,37 & & \\
\hline 16.Venho porque eu gosto de vir à escola & & & & & 0,71 & \\
\hline 20.Venho porque fico feliz quando estou na escola & & & & & 0,82 & \\
\hline 25.Venho à escola porque me sinto bem aqui & & & & & 0,81 & \\
\hline 29.Venho à escola porque acho legal aprender & & & & & 0,55 & \\
\hline 5.Venho à escola porque sinto prazer em aprender coisas novas & & & & & 0,41 & \\
\hline
\end{tabular}


$\mathrm{Na}$ Tabela 3 pode-se identificar a distribuição dos escores obtidos com toda a amostra de alunos nas diferentes variáveis motivacionais. Além disso, o que é mais relevante na presente análise, levantaram-se as correlações de Pearson entre as médias dos escores obtidos pelos participantes na diferentes subescalas, que podem ser observadas na Tabela 4.

Tabela 3 - Resultados das Medidas de Tendência Central Obtidas com a Amostra Inteira (N=1357), em Cada Variável do Continuum da Qualidade Motivacional

\begin{tabular}{lcccccc}
\hline Variável/fator & Média & DP & Mediana & Moda & Mínima & Máxima \\
\hline Desmotivação / 3 & 9,38 & 4,71 & 8,0 & 5,0 & 5,0 & 25,0 \\
Regul. Externa./ 4 & 11,21 & 4,67 & 10,0 & 9,0 & 5,0 & 25,0 \\
Introjetada / 2 & 13,07 & 5,40 & 13,0 & 9,0 & 5,0 & 25,0 \\
Identificada / 1 & 22,41 & 4,02 & 24,0 & 25,0 & 5,0 & 25,0 \\
Mot. Instríns./ 5 & 18,51 & 5,27 & 20,0 & 25,0 & 5,0 & 25,0 \\
\hline
\end{tabular}

As correlações positivas entre desmotivação e motivação extrínseca, tanto na modalidade de regulação externa como na introjetada, sugerem que têm elementos em comum, ou seja, os alunos tendem a revelar combinações parciais dessas formas motivacionais. Por outro lado, e com valor mais alto, desmotivação apareceu negativamente relacionada com motivação identificada e com motivação intrínseca. Note-se também que motivação por regulação identificada é uma forma de motivação autônoma (Bzuneck \& Guimarães, 2010), coerentemente relacionada em nível significativo com motivação intrínseca, que é a modalidade por excelência de motivação autônoma ou autorregulada.

Tabela 4 - Matriz de Correlação de Pearson entre os Escores Médios nas Variáveis da Qualidade da Motivação $(N=1357)$

\begin{tabular}{lccccc}
\hline \multicolumn{1}{c}{ Variáveis } & 1 & 2 & 3 & 4 & 5 \\
\hline Desmotivação & - & $0,40^{* *}$ & $0,52^{* *}$ & $-0,41^{* *}$ & $-0,55^{* *}$ \\
Regul. externa & & - & $0,55^{* *}$ & $-0,05$ & $-0,04$ \\
Regul. Introjet. & & & - & $-0,12^{* * *}$ & $-0,16^{* * *}$ \\
Regul. Identif. & & & & & $0,61^{* *}$ \\
Mot. Intrínseca & & & & & - \\
\hline
\end{tabular}

Por último, foi solicitado que cada aluno revelasse sua percepção do desempenho global acadêmico na escola, marcando-o numa escala de zero a 10. Sobre esses valores declarados foram levantadas as correlações com os escores médios nas variáveis motivacionais. Como resultado, apareceu correlação negativa e significativa entre desempenho percebido e desmotivação $(r=-0,30)$, regulação externa $(r=-0,09)$ e regulação introjetada $(r=-0,18)$. Pelo contrário, foram positivas e significativas, embora em nível moderado, as correlações do desempenho percebido com motivação identificada $(r=0,27)$ e motivação intrínseca $(r=0,32)$.

\section{Discussão}

Desenvolver um questionário com validade psicométrica e que avaliasse a qualidade motivacional de alunos foi o propósito deste estudo. A adoção do referencial teórico da autodeterminação constituiu um diferencial interessante, comparada com outras pesquisas que consideravam apenas a dicotomia entre motivação intrínseca e extrínseca. Como a Teoria da Autodeterminação tem recebido amplo suporte de inúmeros estudos, seus componentes e conceitos representam uma relevante e clara orientação para novas pesquisas sobre motivação, inclusive para a construção de instrumentos de medida desse constructo.

A iniciativa de se ter buscado junto a alunos indicadores concretos de motivação ou desmotivação foi o primeiro procedimento para a construção da escala. As entrevistas com as crianças foram fundamentais para uma aproximação da redação dos itens tanto com o vocabulário delas como com a sua realidade e suas preocupações. Por exemplo, a frase venho para a escola porque é importante para meu futuro é exemplo de um item extraído dessas entrevistas, o qual, possivelmente, não teria sido incluído com base na suposição de que a perspectiva de futuro seria impensável em relação a crianças daquelas faixas de idade.

No presente estudo, exploraram-se instrumentos já existentes e que também visavam a 
avaliar motivação de alunos em sentido qualitativo (Arcas, 2003; Guimarães \& Bzuneck, 2008; Harter, 1981; Lepper e colaboradores, 2005; Neves \& Boruchovich, 2004; 2007; Sobral, 2003; Vallerand e colaboradores, 1992). A consideração da teoria, já naquela fase, porém, teve o importante papel de dirigir a escolha de itens que representassem os pontos do continuum. Uma boa teoria inspira boas pesquisas e, uma vez obtidos os dados através da investigação, possibilita uma compreensão mais cabal dos resultados. Sem a teoria, tanto os itens de um questionário como as próprias descobertas através de sua aplicação teriam significado muito reduzido, talvez até equivocados.

A análise fatorial exploratória, através do levantamento dos componentes principais, propiciou a conclusão de que o instrumento criado goza das propriedades psicométricas desejáveis, atingindo a validade de constructo, relativamente aos pressupostos teóricos. Foram também satisfatórias as cargas fatoriais de cada um dos itens relacionados a cada um dos cinco fatores A explicação da variância das respostas aos cinco fatores considerados na escala foi de 59,20, superior aos resultados obtidos nas pesquisas citadas anteriormente. Os índices de consistência interna dos itens de cada fator, pelo alpha de Cronbach, são adequados para uso em pesquisas e, por último, as correlações entre as subescalas confirmam o modelo de continuum de autodeterminação, previsto teoricamente.

Considerando a existência do continuum crescente de autodeterminação, as subescalas adjacentes, ou seja, a desmotivação, motivação por regulação externa e introjetada deveriam ser correlacionadas de modo positivo e significativo. Ao mesmo tempo, a hipótese era de que seriam positivas e significativas as correlações entre motivação extrínseca por regulação identificada e motivação intrínseca. Além disso, correlações negativas eram esperadas entre os escores dos itens das subescalas dos extremos opostos, ou seja, entre os itens representativos de motivação controlada externamente e os da motivação autônoma. Todas essas previsões comprovaram-se nas presentes análises, ou seja, os tipos alocados em extremos opostos no continuum obtiveram correlações negativas e os próximos, correlações positivas, um resultado que evidencia mais um aspecto da validade do instrumento.

Adicionalmente, como contribuição para a validade externa do instrumento, surgiram relações coerentes entre os escores nos itens do continum e a declaração dada pelos alunos de seu grau de desempenho global nas aprendizagens escolares. Como a motivação é constructo que responde pelo esforço e engajamento perseverante dos alunos nas atividades de aprendizagem, sua presença e qualidade respondem, ao menos em parte, pela autopercepção de rendimento acadêmico. Dignas de nota foram as relações negativas entre a desmotivação e as formas de motivação controlada, por um lado, e o desempenho alegado, por outro lado. E foram positivas as relações entre os tipos de motivação autônoma, qualitativamente superiores, e o desempenho percebido.

Um último aspecto a ser destacado refere-se ao formato da escala e ao modo dos alunos responderem. Seguindo sugestão de Lepper e colaboradores (2005), a escala de cinco pontos foi apresentada com cinco quadrinhos de tamanhos crescentes, com os números colocados abaixo deles, o que parece ter contribuído para a compreensão por parte dos alunos. Um exemplo de uma situação cotidiana, ir ao cinema, serviu de treino para a execução da tarefa.

\section{Considerações Finais}

Em que pesem os diversos aspectos positivos do estudo, suas limitações devem ser reconhecidas. Alguns itens do questionário podem ser aprimorados ou substituídos, para se conseguir maior índice de fidedignidade em alguma subescala. Outra limitação tem relação com o teor do objeto da motivação, avaliada qualitativamente no questionário. Os itens acenavam com motivação para vir para a escola, logo, para um comportamento de significado muito amplo que, inquestionavelmente, incluía aprender na escola tudo o que nela for ensinado. É uma perspectiva valida porque a motivação pode ser entendida em relação a todas as aprendizagens escolares. Em algumas pesquisas (por exemplo, Sobral, 2003; Vallerand \& colaboradores., 1992) os autores trabalharam com esse objetivo. Por outro lado, outros pesquisadores têm optado por investigar a motivação para disciplinas específicas ou para tópicos (Bong, 2001; Ryan \& Patrick, 2001, entre outros), já que especificidades de exigências e de conteúdo costumam estar ligadas a possíveis problemas de motivação. Por conseguinte, sugere-se uma adaptação do presente questionário focalizando, por exemplo, aprendizagem de matemática, ou leitura, produção de textos etc., com resultados educacionalmente relevantes.

Deve-se ainda reconhecer a limitação ligada ao método de se avaliar o desempenho acadêmico através das autodeclarações dos alunos. Embora os alunos possam ter uma impressão objetiva de seu rendimento escolar, os presentes resultados devem ser olhados com cautela. Em primeiro lugar, as notas de zero a dez alegadas podem não ter relação com o desempenho real, aferido por uma fonte independente, aliás, difícil de conseguir. $\mathrm{O}$ viés de autoapresentação socialmente aceitável pode ter conduzido alunos a se mostrarem 
mais bem sucedidos do que têm sido de fato. Mas o maior problema subjacente deriva da falta de especificidade das disciplinas. Certos alunos podem ter mau desempenho apenas em alguma disciplina, o que ficaria encoberto numa avaliação global, baseada no êxito em outras disciplinas. Em outras palavras, faltam dados para uma consideração efetiva dos efeitos da motivação em termos de resultados.

Não obstante tais apontamentos, os resultados do presente estudo parecem contribuir de forma relevante para a área da motivação no contexto escolar, ao apresentar um instrumento brasileiro, voltado a alunos do ensino fundamental. As análises que concluíram por sua validade de contructo e pela fidedignidade dos itens em cada subescala indicam que a escala pode ser utilizada em pesquisas brasileiras, tanto para explorar diferentes situações escolares, como para contribuir para o desenvolvimento e contextualização teórica.

\section{Referências}

Alonso, J. L. N. (2006). Validación de la Escala de Motivación Educativa (EME) en Paraguay. Revista Interamericana de Psicologia/Interamerican Journal of Psychology, 40(2), 185-192.

Arcas, P.H. (2003). Avaliação da aprendizagem no regime de progressão continuada: $O$ que direm os alunos (Dissertação de Mestrado). São Paulo: Universidade Estadual de São Paulo.

Bong, M. (2001). Between and within-domanin relations of academic motivation among middle and high school students: Self-efficacy, task-value, and achievement. Journal of Educational Psychology, 9 (1), 2334.

Bzuneck, J. A. \& Guimarães, S.E.R. (2010). A promoção da autonomia como estratégia motivacional na escola: uma análise teórica e empírica. Em E. Boruchovitch, J.A. Bzuneck \& S.E.R. Guimarães (Orgs.), Motivação para aprender: Aplicações no contexto educativo (pp.43-70). Petrópolis: Vozes.

Csikszentmihalyi, M. (1992). A psicologia da felicidade. São Paulo: Saraiva.

Deci, E. L., \& Ryan, R. M. (1985). Intrinsic motivation and self-determination in human behavior. New York: Plenum Press.

Deci, E. L., \& Ryan, R. M. (1991). A motivational approach to self; integration in personality. Nebraska Symposium on Motivation, 1990-vol. 38: Perspectives in Motivation. Lincoln/Londres: University of Nebraska Press, p. 237-288.

Guimarães, S. E. R. \& Boruchovitch, E. (2004). O Estilo Motivacional do Professor e a Motivação
Intrínseca dos estudantes: Uma Perspectiva da Teoria da Autodeterminação. Psicologia Reflexão e Crítica, 17(2), 143-150.

Guimarães, S.E.R. \& Bzuneck, J.A. (2008) Propriedades psicométricas de um instrumento para avaliação da motivação de universitários. Ciências \& Cognição, 13(1), 101-113.

Harter, S. (1981). A new self-report scale of intrinsic vs. extrinsic orientation in the classroom: Morivational and informational components. Developmental Psychology, 17, 300-312.

Kline, P. (1994) An easy guide to factor analysis. New York: Routledge, 194 p.

Lepper, M. R. \& Henderlong, J. (2000). Turning "play" into "work" and "work" into "play": 25 years of research on intrinsic versus extrinsic motivation. Em C. Sansone \& J. M. Harackiewicz (Orgs.), Intrinsic and Extrinsic Motivation: The search for optimal motivation and performance (pp. 257-307). San Diego: Academic Press.

Lepper, M. R., Henderlong, J. \& Iyengar, S. S. (2005). Intrinsic and Extrinsic Motivational Orientations in the Classroom: Age Differences and Academic Correlates. Journal of Educational Psychology, 97(2), 184-196.

Martinelli, S. C. \& Bartholomeu, D. (2007). Escala de motivação escolar: uma medida de motivação extrínseca e intrínseca. Avaliação Psicológica, 6(1), 21-31.

Martini, M.L. (1999). Atribuiçôes de causalidade, crenças gerais e orientações motivacionais de crianças brasileiras (Dissertação de Mestrado). Campinas: Universidade Estadual de Campinas.

Neves, E. R. C. \& Boruchovitch, E. (2004). A Motivação de Alunos no Contexto da Progressão Continuada. Psicologia: Teoria e Pesquisa, 20(1), 77-85.

Neves, E. R. C. \& Boruchovitch, E. (2007). Escala de avaliação da motivação para aprender de alunos do ensino fundamental (EMA). Psicologia: Reflexão e Crítica, 3(2),421-428.

Niemiec, C. P., Lynch, M. F., Vansteenkiste, M., Bernstein, J., Deci, E. L., \& Ryan, R. M. (2006). The antecedents and consequences of autonomous self-regulation for college: A self-determination theory perspective on socialization. Journal of Adolescence, 29, 761-775.

Reeve, J., Deci, E. L. \& Ryan, R. M. (2004). Self-Determination Theory. A dialectical framework for understand sociocultural influences on student motivation. Em D. M. McInerney \& S. Van Etten (Orgs.), Big Theories Revisited (31-58). Connecticut: Age Publishing.

Reeve, J. (2004). Self-determination theory applied to educational settings. Em E. L. Deci \& R. M. Ryan (Orgs.), Handbook of self-determination research (183-203). New York: University of Rochester Press. 
Ryan, A.M. \& Patrick, H. (2001). The classroom social environment and changes on adolescents' motivation and engagement during middle school. American Educational Research Journal, 38 (2), 437-460.

Ryan, R. M. \& Deci, E. (2000). Selfdetermination theory and the facilitation of intrinsic motivation, social development, and well-being. American Psychologist, 55(1), 68-78.

Sobral, D. T. (2003). Motivação do Aprendiz de Medicina: Uso da Escala de Motivação Acadêmica. Psicologia: Teoria e Pesquisa, 19(1), 25-31.
Vallerand, R.J., Pelletier, L.G., Blais, M.R., Brière, N.M., Senécal, C. \& Vallières, E.F. (1992). The Academic Motivation Scale: a measure of intrinsic, extrinsic, and amotivation in education, Educational and Psychological Measurement, 52, 1003-1017.

Sobre os autores:

Sueli Édi Rufini é Graduada em Psicologia, com doutorado em Educação pela Universidade Estadual de Campinas (2003). Professora da Universidade Estadual de Londrina onde atua em cursos de formação de professores e no Programa de Mestrado em Educação. Coordenadora de Projeto PROCAD em parceria com a Faculdade de Educação/UNICAMP. Bolsista de Produtividade em Pesquisa do CNPq - Nível 2.

José Aloyseo Bzuneck é Graduado em Filosofia, com doutorado em Psicologia Escolar e do Desenvolvimento Humano pela Universidade de São Paulo (1980). É professor Sênior na Universidade Estadual de Londrina, onde atua no Programa de Mestrado em Educação. Desenvolve e orienta pesquisas acerca da motivação no contexto escolar, dá assistência regular a escolas e sistemas de ensino, com palestras e oficinas.

Katya Luciane de Oliveira é Psicóloga, com doutorado em Psicologia, Desenvolvimento Humano e Educação pela Faculdade de Educação da Universidade Estadual de Campinas. É professora da Universidade Estadual de Londrina, onde atua no Departamento de Psicologia e no Mestrado em Educação. Tem experiência na área de Psicologia escolar e na Construção e validação de testes, escalas e outras medidas psicológicas. É bolsista da Fundação Araucária. 